\title{
Production of Diiodohydroxyphenylpyruvic Acid from Diiodotyrosine by Nonenzymatic Reaction*
}

\author{
Shuhei ITO, KeI SEO, KaOru SANO AND Mitsuo NISHIKAWA \\ Second Department of Internal Medicine, Osaka University Medical School, Osaka.
}

\section{Synopsis}

\begin{abstract}
The nonenzymatic synthesis of 4-hydroxy-3, 5-diiodophenylpyruvic acid (DIHPPA) from diiodotyrosine is reported in this paper. The reaction was carried out in vitro in the presence of pyridoxal and metal ion. The yield of DIHPPA at $37^{\circ} \mathrm{C}$ for 2 hrs. and at $100^{\circ} \mathrm{C}$ for 30 mins. were almost the same. Among metal ions used in the present study, $\mathrm{Cu}^{++}$was found to be most effective. $\mathrm{Co}^{++}$was also effective, while other ions, $\mathrm{Al}^{+++}, \mathrm{Zn}^{++}, \mathrm{Mn}^{++}, \mathrm{Ni}^{++}, \mathrm{Fe}^{++}$and $\mathrm{Fe}^{+++}$were only very slightly effective. The results obtained in this study suggest that the nonenzymatic reaction possibly takes place also in vivo.
\end{abstract}

It has been suggested that thyroxine $\left(\mathrm{T}_{4}\right)$ is synthesized from the reaction between 3,5diiodotyrosine (DIT) and 4-hydroxy-3,5diiodophenylpyruvic acid (DIHPPA), which is formed by the action of 1-amino acid oxidase (Yip and Klebanoff, 1962) or peroxidase (Harrath, 1962) on DIT (Meltzer and Stanaback, 1961; Toi et al., 1963). The nonenzymatic conversion of DIT to $\mathrm{T}_{4}$ in the presence of DIHPPA and oxygen was reported by several authors (Toi et al., 1963; Hillmann, 1956; Shiba and Cahnmann, 1962). It is the purpose of the present study to investigate if the conversion of DIT to DIHPPA takes place also in the absence of any enzyme.

Received for publication December 7, 1968.

* Dedicated to professor Yosoji ITO in commemoration of his unselfish devotion for over fifteen years to the advancement of endocrinological science, through the editorial management of Endocrinologia Japonica.

\section{Materials and Methods \\ Enzymatic synthesis of DIHPPA}

Experiments were carried out in vitro by using a slight modification of the method of Fisher et al. (1965). One $\mu \mathrm{Ci}$ of ${ }^{131}$ I-DIT obtained from RCC was added to the incubation medium consisting of $10 \mathrm{mM}$ l-DIT, $1.67 \mathrm{mM}$ pyridoxal phosphate, $3.33 \mathrm{~m} M$ $\mathrm{MgCl}_{2}, 10 \mathrm{~m} M$ d-glucose, $16.7 \mathrm{~m} M$ Tris(hydroxy-methyl)aminomethane, $0.67 \mathrm{~m} M$ ethylenediamine tetraacetate, $200 \mu \mathrm{g}$ of glucose oxidase and $25 \mathrm{mg}$ of bovine thyroid microsomal protein (Fischer et al., 1963). The final volume was $3 \mathrm{ml}$ and the $\mathrm{pH}$ was adjusted to 8.5 . After incubation at $32^{\circ} \mathrm{C}$ for $2 \mathrm{hrs}$, the reaction was stopped by the addition of $1 \mathrm{ml}$ of 2.5 $M$ hydroxylamine hydrochloride. The acidic mixture was thoroughly extracted with n-butanol saturated with $\mathrm{H}_{2} \mathrm{O}$. The butanol extract was evaporated to dryness and the residue was dissolved in 0.2 $\mathrm{ml}$ of $30 \%$ alcoholic $\mathrm{NH}_{4} \mathrm{OH}$. Samples were chromatographed on Toyo No. 50 filter paper in a solvent system of n-butanol-acetic acid- $\mathrm{H}_{2} \mathrm{O}$ (78: $5: 17$ ). Spots were detected by staining with Mandl-Block's method for iodide (Mandl and Block, 1959). The paper was then cut into pieces of $0.5 \mathrm{~cm}$ in width and the radioactivity of each piece was determined by a 
Nuclear Chicago Scintillation Counter. The paper was then extracted with alkaline solution, and the quantity of each component was determined spectrophotometrically by using a Hitachi-UV Spectrophotometer.

\section{Nonenzymatic synthesis of DIHPPA}

One $\mu \mathrm{C} i$ of 131 I-DIT was added to the medium consisting of $10 \mathrm{~m} M l$ - DIT, $20 \mathrm{mM}$ pyridoxal hydrochloride and $5 \mathrm{~m} M$ metal ion. Metal ions used in these experiments were $\mathrm{Cu}^{++}\left(\mathrm{Cu}\left(\mathrm{NO}_{3}\right)_{2}\right), \mathrm{Co}^{++}\left(\mathrm{CoCl}_{2}\right)$, $\mathrm{Al}^{+++}\left(\mathrm{AlCl}_{3}\right), \mathrm{Zn}{ }^{++}(\mathrm{ZnSO} 4), \mathrm{Mn}^{++}\left(\mathrm{MnCl}_{2}\right), \mathrm{Ni}^{++}$ $\left(\mathrm{NiCl}_{2}\right), \mathrm{Fe}^{++}\left(\mathrm{FeSO}_{4}\right)$ and $\mathrm{Fe}^{+++}\left(\mathrm{FeCl}_{3}\right)$. The total volume was $4 \mathrm{ml}$ and the $\mathrm{pH}$ adjusted to 5.0, 7.0, 7.5, 8.0 and 10.0. After incubation at $37^{\circ} \mathrm{C}$ for $2 \mathrm{hrs}$. or at $100^{\circ} \mathrm{C}$ for 30 mins., the sample was made alkaline by the addition of $0.04 M \mathrm{KOH}$. The sample was immediately applied on Toyo No. 50 filter paper and chromatographed in a solvent system of dioxanen-butanol-2 $\mathrm{N} \mathrm{NH}_{4} \mathrm{OH}$ (1: 4: 2), of sec. butanol-3.2N $\mathrm{NH}_{4} \mathrm{OH}(3: 1)$ or of n-butanol-acetic acid- $\mathrm{H}_{2} \mathrm{O}(78: 5$ : 17). Further procedures for the measurement of the radioactivity were the same as used in the enzymic study. The identification of DIHPPA was performed by $\mathrm{Rf}$ on paper chromatogram and by the presence of maximal absorption at $340 \mathrm{~m} \mu$.

\section{Results}

\section{1) Enzymatic conversion of DIT}

On paper chromatography developed with n-butanol-acetic acid- $\mathrm{H}_{2} \mathrm{O}$, DIHPPA migrates very close to the spot of $T_{4}$. These two spots were combined together as a reaction product from DIT.

The yield of the reaction product calculated in terms of the ratio of the radioactivity of the reaction product to the sum of the reaction product and DIT was about $20 \%$ in the presence of thyroid microsomal protein. About

Table 1. Effect of compositions of medium on yield of $\mathrm{T}_{4}$ performed by the modified method of Fischer et al.

\begin{tabular}{|c|c|}
\hline Composition of medium & $\frac{\mathrm{T}_{4}}{\mathrm{DIT}+\mathrm{T}_{4}} \%$ \\
\hline presence of thyroid microsome & 20.0 \\
\hline absence of thy roid microsome & 19.3 \\
\hline $\begin{array}{l}\text { presence of thy roid microsome } \\
\text { boiled for } 20 \mathrm{~min} \text {. }\end{array}$ & 17.1 \\
\hline without pyridoxal & 3.9 \\
\hline
\end{tabular}

the same yields were obtained without thyroid microsomes as well as when the microsomes added were boiled at $100^{\circ} \mathrm{C}$ for 20 mins. before use. Withdrawal of pyridoxal from the incubation medium markedly decreased the yield of the reaction product (Table 1). a

F b

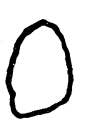

C

0

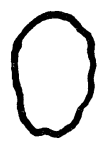

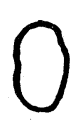

0

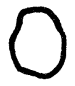

DIT

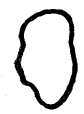

I

O

Fig. 1. Paperchromatogram of mixture consisted of DIT, pyridoxal hydrochloride and $\mathrm{Cu}$ $\left(\mathrm{NO}_{3}\right)_{2}$ developed in a solvent system of dioxane-n-butanol- $2 \mathrm{~N}_{4} \mathrm{NH}_{4} \mathrm{OH}$

a: chromatogram of mixture

b: chromatogram after addition of alkaline solution to mixture

c: chromatogram of DIHPPA in ethanol 


\section{2) Nonenzymatic conversion of DIT into DIHPPA.}

\section{Chromatographic behavior of DIT in the reaction mixture}

When the reaction mixture of DIT, pyridoxal and metal ion in neutral or acidic medium was applied on paper chromatography, a spot of $\mathrm{Rf} 0.5$ was detected with iodide staining in addition to the spot of original DIT (Fig. 1a). When the mixture was made alkaline and then chromatographically analyzed, another spot of Rf 0.8 appeared (Fig. 1b). The latter spot of Rf 0.8 was identified as DIHPPA (Fig. 1c). Presumably, the spot of Rf 0.5 was diiodotyrosine-pyridoxal-metal complex, and this complex was easily decomposed into diiodohydroxybenzaldehyde and pyridoxamine in alkaline solution.

\section{Conversion of DIT into DIHPPA during incubation}

When the mixture of DIT. pyridoxal and $\mathrm{Cu}^{++}$was made alkaline and immediately analyzed on chromatography, $7.7 \%$ of DIT was converted into DIHPPA. When the mixture was incubated at $37^{\circ} \mathrm{C}$ for $2 \mathrm{hrs}$. at $\mathrm{pH} 7.5$ and then treated with alkaline, $10.2 \%$ of the original radioactivity appeared with DIHPPA (Table 2).
At $\mathrm{pH}$ between 5.0 and 8.0 , the net synthesis of DIHPPA was almost constant (Table 3). At pH higer than 10.0, the yield of DIHPPA was slightly increased.

\section{Effect of metal ions}

The mixture of DIT and pyridoxal was incubated at $37^{\circ} \mathrm{C}$ for 2 hrs. at $\mathrm{pH} 7.5$ in the presence of various metal ions. The sample was then made alkaline and analyzed on paper chromatography. The presence of $\mathrm{Cu}^{++}$or $\mathrm{Co}^{++}$were favorable for the conversion of DIT into DHPPA, while the other metal ions did not show a marked effect on the conversion even in the alkaline medium (Fig. 2).

Table 3. Effect of $\mathrm{pH}$ on yield of DIHPPA from DIT

\begin{tabular}{rc}
\hline $\mathrm{pH}$ & yield of DIHPPA $(\%)^{*}$ \\
\hline 5.0 & 10.1 \\
7.0 & 10.2 \\
7.5 & 10.2 \\
8.0 & 10.2 \\
10.0 & 11.3 \\
\hline
\end{tabular}

* see Table 2.

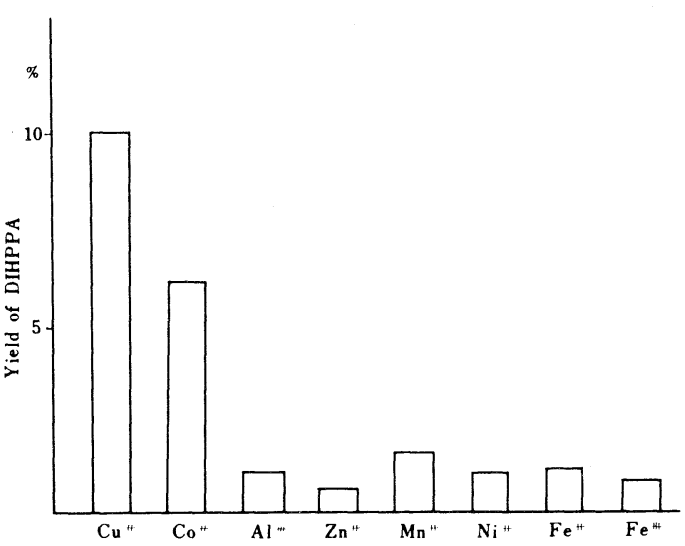

Fig. 2. Effect of metal ions on yield of DIHPPA
When the mixture was treated at $100^{\circ} \mathrm{C}$ for 30 mins. and then made alkaline, $12.2 \%$ of the original radioactivity was found with DIHPPA.

3. Effect of $p H$ on the conversion of DIT into DIHPPA during the incu-

bation

Effect of
DIHPPA

\begin{tabular}{lc}
\hline Condition of incubation & yield of DIHPPA (\%)* \\
\hline immediately after sampling & 7.7 \\
at $37^{\circ} \mathrm{C}$ for $2 \mathrm{hrs}$. & 10.2 \\
at $100^{\circ} \mathrm{C}$ for $30 \mathrm{~min}$. & 12.2 \\
\hline
\end{tabular}

*yield of DIHPPA

$=\frac{\text { radioactivity in area of DIHPPA }}{\text { total radioactivity on paper chromatographed }}$ 


\section{Discussion}

The precise mechanism of the synthesis of thyroxine from diiodotyrosine has not yet been established. The following pathways have been proposed (De Groot, 1966):

1) The formation of dityrosine by peroxidase attack (Gross and Sizer, 1959).

2) 2,6-diiodobenzoquinone producted by the action of peroxidase on DIT is an intermetabolite of $\mathrm{T}_{4}$ synthesis (Ljunggren, 1963).

3) $T_{4}$ is synthesized through the coupling of DIT and DIHPPA which is formed by the action of 1-amino acid oxidase (Yip and Klebanoff, 1962) or of peroxidase (Harrath, 1962) on DIT (Fischer et al., 1966).

4) The oxidation of tyramine by monoamine oxidase provides hydrogen peroxide required for iodination of tyrosine and iodothyronine synthesis.

Among these hypothesis, the synthesis of $\mathrm{T}_{4}$ through the coupling of DIT and DIHPPA has been supported by more convincing evidences. DIHPPA was detected in the normal thyroid tissue (Haney and Lissitzky, 1962; Surks et al., 1968). Nonenzymatic synthesis of $\mathrm{T}_{4}$ from the reaction between DIT and DIHPPA in vitro was reported by Hilmann, by Toi and by Shiba independently. The reaction possibly takes place also in vivo in physiological conditions. DIHPPA was chemically synthesized by Bergmann et al., (1931) and by Tong et al., (1954). However, the conditions used for the chemical synthesis were not so mild as might be expected for bio-synthesis.

The results of the present investigation reveal that DIHPPA was formed nonenzymatically with a considerably high yield from DIT in a simple medium containing pyridoxal and $\mathrm{Cu}^{++}$. Snell and Jenkens (1959) presented a schematical illustration of the catalytic effect of pyridoxal on the conversion of amino acid into the corresponding keto compound. The conversion of DIT into DIHPPA can also be explained by the same mechanism. Present data agree well with the results of Longenecker and
Snell (1957) showing that $\mathrm{Cu}^{++}$demonstrates the most potent action for chelation and catalysis in transamination reaction involving amino acid.

\section{References}

Bergmann, M., L. Zervas and F. Lebrecht (1931). Ber. 64, 2315.

De Groot, L. J. (1966). New Engl. J. of Med. 272,255

Fisher, A.G., A.R. Schultz and L. Oliner (1963). Biochem. Biophys Research Communs. 14, 39.

Fischer, A.G., A.R. Schultz and L. Oliner (1965). J. Biol. Chem. 240, 4338.

Fischer, A.G., A.R. Schultz and L. Oliner (1966). Life Science 5, 995.

Gross, A.J. and I. W. Sizer (1959). J. Biol. Chem. 234, 1611.

Haney, J.F.B. and S. Lissitzky (1962). Biochim. Biophys. Acta 63,557.

Harrath, A. (1962). Enzymologia 25, 32.

Hillmann, G. (1956). J. Naturforschung 11, 474.

Longenecker, J. B. and E. E. Snell (1957). J. Am. Chem. Soc. 79, 142.

Ljunggren, J. G. (1963). Acta Chem. Scand. 17, 567.

Mandl, R. H. and R. J. Block (1959). Arch. Biochem. Biophys. 81, 25.

Meltzer, R. I. and R. J. Stanaback (1961). J. Org. Chem. 26, 1977.

Snell, E. E. and W. T. Jenkins (1959). J. Cellular and Comparative Physiology 54, Supple. 1: 161.

Shiba, T. and H. J. Cahnmann (1962). J. Org. Chem. 27, 1773.

Surks, M. I., S. Weinbach and E. M. Volpert (1968). Endocrinology 82, 1156.

Tong, W., A. Taurog and I. L. Chaikoff (1954). J. Biol. Chem. 207, 59.

Toi, K., G. Salvatore and H. J. Cahnmann (1963). Biochim. Biophys. Acta 78, 805.

Yip, C. and S. Klebanoff (1962). Endocrinology 70, 931 . 